\title{
Formalizing best practice for energy system optimization modelling
}

\author{
Joseph DeCarolis ${ }^{\mathrm{a}, 1}$, Hannah Daly ${ }^{\mathrm{b}}$, Paul Dodds ${ }^{\mathrm{c}}$, Ilkka Keppo ${ }^{\mathrm{c}}$, Francis $\mathrm{Li}^{\mathrm{c}}$, Will McDowall ${ }^{\mathrm{c}}$, \\ Steve Pye ${ }^{c}$, Neil Strachan ${ }^{c}$, Evelina Trutnevyte ${ }^{\mathrm{d}}$, Will Usher ${ }^{\mathrm{e}}$, Matthew Winning ${ }^{\mathrm{c}}$, Sonia Yeh ${ }^{\mathrm{f}}$, \\ Marianne Zeyringer ${ }^{c}$ \\ ${ }^{a}$ Department of Civil, Construction, and Environmental Engineering, NC State University, USA \\ ${ }^{\mathrm{b}}$ International Energy Agency, France \\ ${ }^{\mathrm{c}}$ University College London (UCL) Energy Institute, UK \\ ${ }^{\mathrm{d}}$ Department of Environmental Systems Science, ETH Zürich, Switzerland \\ ${ }^{\mathrm{e}}$ Environmental Change Institute, University of Oxford, UK \\ ${ }^{\mathrm{f}}$ Department of Energy and Environment, Chalmers University of Technology, Gothenburg, \\ Sweden
}

\begin{abstract}
Energy system optimization models (ESOMs) are widely used to generate insight that informs energy and environmental policy. Using ESOMs to produce policy-relevant insight requires significant modeler judgement, yet little formal guidance exists on how to conduct analysis with ESOMs. To address this shortcoming, we draw on our collective modelling experience and conduct an extensive literature review to formalize best practice for energy system optimization modelling. We begin by articulating a set of overarching principles that can be used to guide ESOM-based analysis. To help operationalize the guiding principles, we outline and explain critical steps in the modeling process, including how to formulate research questions, set spatiotemporal boundaries, consider appropriate model features, conduct and refine the analysis, quantify uncertainty, and communicate insights. We highlight the need to develop and refine formal guidance on ESOM application, which comes at a critical time as ESOMs are being used to inform national climate targets.
\end{abstract}

Keywords: energy system models, uncertainty, modelling guidance

${ }^{1}$ Corresponding author: email: jdecarolis@ ncsu.edu, phone: +1 919515 0480, fax: +1 9195157908 


\section{Introduction}

Sustainable energy development worldwide requires us to anticipate and shape possible future outcomes under a variety of different scenarios that consider resource availability and pricing, technology innovation, demand growth, and new energy and environmental policy. Computer models represent a critical tool that can be used to examine the future decision space under a variety of different assumptions. Energy infrastructure is long-lived, so model scenarios that aim to show significant turnover in capital stock in response to new policy must span multiple decades. However, given large future uncertainties that grow with time, using models to produce narrowly focused quantitative predictions is a perilous approach that often produces misleading conclusions. For example, retrospective analysis of energy demand projections generally shows a poor match to reality [1-4]. Even with more modeling experience, higher quality input data, and improved computational resources, model results covering multiple decades cannot be validated, making it hard to create a feedback loop that links model improvements to more accurate projections $[1,5,6]$. Thus the goal of energy modeling should be insights that challenge our working assumptions and mental models rather than a limited set of quantitative predictions [79]

Given the complexity of the modeled system and the inability to validate model results, energy modeling requires a significant amount of modeler judgment that - depending on one's perspective - makes energy modeling a blend of art and science [6] or a craft that is neither art nor science [10]. A variety of methodological approaches and models exist, each with their own strengths and weaknesses that are adapted to answer specific types of questions. Several past efforts have characterized the distinctions between different energy model types (e.g., [11,12].

Within the field of energy modeling, energy system optimization models (ESOMs) are widely used to model the system-wide impacts of energy development using a self-consistent framework for evaluation. ESOMs include detailed, bottom-up technology specifications and utilize linear programming techniques to minimize the system-wide present cost of energy provision by optimizing the installation of energy technology capacity and its utilization. The models are subject to a number of constraints that enforce system performance criteria as well as userdefined limits. Outputs include future estimates of technology capacity and utilization, marginal commodity prices, and emissions across the energy system. Example ESOMs include ESME [13], the MARKAL/TIMES model generators [14,15], MESSAGE [16], OSeMOSYS [17], and Temoa [18]. In their basic form, ESOMs assume perfect foresight and optimize the energy system from a social planning perspective, thus producing ideal, normative results that can lead to policy-relevant insights. ESOMs have several analytical strengths. First, they provide a consistent accounting framework for specifying the techno-economic performance characteristics of all modeled processes. Second, the model formulation allows for quick and efficient normative goal seeking within highly complex systems. Third, the results can suggest a wide range of energy futures that reflect energy and environmental policy objectives. Fourth, ESOMs can capture sectoral interactions that can lead to cross-cutting insights, which are hard to capture in sector-specific models.

However, given the broad scope of ESOMs, they have become a magnet for increasing complexity as different approaches and features are developed to improve the realism associated with internal model dynamics. Examples include price-responsive demands, hurdle rates, 
macroeconomic feedbacks, and endogenous technological learning. Various model features and their theoretical underpinnings have been documented elsewhere (e.g., $[14,15,19])$, and in some cases, critical reviews of specific model elements, such as the discount rates [20] and energy efficiency [21] have been performed. Other studies review and provide high-level guidance on a broader range of energy models that can be used to inform policy [22]. However, a crucial gap remains: there is no published best practice guidance focused on the application of ESOMs, including how and when particular model features should be applied. Such decisions are modeland analysis-specific, and depend on reasoned judgment rather than objective rules. More generally, each modeler must make their own decisions about how to develop and apply ESOMs. Over time, this has led to a crowded landscape of model-based analyses that can overwhelm decision makers with their complexity.

Reflecting on our own experience with ESOMs over the last decade, we see a critical need to compile and synthesize the undocumented knowledge and reasoning behind effective modelbased analysis. This review paper represents the first effort to formalize best practice associated with the application of energy system optimization models (ESOMs), which play a critical role in policy analysis. We draw on our collective experience with ESOMs as well as an extensive body of literature and synthesize it into a practical guide for energy modelling. We begin by articulating a set of overarching principles that can be used to guide ESOM-based analysis. To help operationalize the guiding principles, we outline and explain critical steps in the modelling process, including how to formulate research questions, set spatio-temporal boundaries, consider appropriate model features, conduct and refine the analysis, quantify uncertainty, and communicate insights. While the energy community has rightly focused on specific model applications to inform energy decision making, there is also a need to document the approach to ESOM applications in a way that maximizes transparency and engenders trust among those who rely on model-based results. This paper fulfills three currently unmet objectives: it provides guidance to new modelers, initiates a community-wide effort to establish and refine modelling guidelines, and fosters understanding among policy makers and analysts, who should be informed consumers of ESOM-based analysis. While this paper focuses on ESOMs, the recommendations are broadly applicable to other modelling tools used to inform energy and environmental decision making.

\section{Guiding principles for ESOM-based analysis}

ESOM-based analysis should be driven by a limited set of guiding principles. The guidelines presented here are inspired by the ten commandments of good policy analysis articulated by Morgan and Henrion [23] as well as recommendations provided by Craig et al. [1] related to energy forecasting. We have adapted these recommendations to the application of ESOMs.

I. Let the problem drive the analysis, not the other way around. This is arguably the most important guideline when conducting energy systems analysis with data intensive models. As development time and experience grows with a particular model, there is a tendency to use the same tool to address different problems, even when it may not be the best option. Modelers must fight this temptation of convenience, and carefully evaluate the model required by the motivating questions. Modelers must ensure that ESOMs are fit for their purpose and should be adapted to suit the problem at hand. In some cases, the ESOM may need to be abandoned altogether if its capabilities do not align with the research questions. 
II. Make the analysis as simple as possible and as complex as necessary. Modelers must be cognizant of the complexity and data intensiveness of their models, particularly as they appear to non-modelers interested in the results of model-based analysis. Because the most convincing models and analyses are often the easiest to comprehend, parsimony should always be a goal. In this context, we make a distinction between complication and complexity: the former is unnecessary and should be avoided, while the latter is required when an honest accounting of the driving questions requires it. Sensitivity analysis (Section 3.5.2) could be used to identify critical model features that lead to important changes in the modelling outcomes of interest. Such model introspection helps to keep the focus on the model improvements that produce a significant difference in the results.

III. Develop quality assurance procedures and apply them to input data. ESOMs are necessarily data intensive, requiring the specification of technology-specific input cost and performance data that ranges from energy supply through end use demands. Data quality is highly variable, yet formal efforts to develop and apply quality assurance procedures to ESOM input data are lacking. Government agencies typically have detailed data quality assurance programs, which can be adapted to the needs of energy modelers. For example, HM Treasury [24] outline several quality assurance activities, including version control, analyst-led testing, peer reviews, and audits. Formalized methods to rate data quality should also be considered. For example, the pedigree matrix approach has been developed to code qualitative judgements about data into numerical scores [25], and has been adopted within the LCA community to code uncertainty about flows within the ecoinvent 3 database [26].

IV. Consider the range of sectoral detail across the model. When constructing a new ESOM dataset, a simple system should first be developed and tested. Sectoral detail should be added - as needed - in a structured, piecewise approach that ensures the level of detail across the model is appropriate for a given analysis. There are no objective rules that one can follow; rather, it necessarily relies on modeler judgment. Over time, careful model management is required to avoid a slow creep toward increased complexity as the vestiges of past analyses are retained within the model. Some model sectors may accrue more detail over time in response to project-specific needs. Efforts to assess the appropriate level of sectoral detail within a model should be conducted regularly [27]. 'Model archeology' can be employed to ensure that data development is consistent and unbiased over time [28] and can be aided with the use of version control software [6]. In their role as book keeping devices, energy models can also help prioritize the collection of empirical data in areas found to be lacking [1].

V. Re-evaluate the modelling approach and objectives throughout the analysis. As with any analysis, modelers design an analysis based on a set of objectives and hypotheses about how they think the modeled system will respond. As the analysis proceeds and model results are processed, the research questions and hypotheses may need to be refined. The need to iteratively refine research questions in light of new results is common to most forms of quantitative analysis, including policy analysis [23] and life cycle assessment [29].

VI. Consider uncertainties that are both endogenous and exogenous to the model and how they can affect conclusions. Both structural and parametric uncertainty abounds in long term energy projections. Modelers should expend effort to quantify key sensitivities and uncertainties within the model. Even with a rigorous accounting of uncertainty, 
modelers should be aware of false precision in the results. Given the high dimensionality of the decision space, it is difficult to account for all relevant uncertainties. Modelers should work to ensure that insights are supported by the model approach and results. Care should be taken to outline the caveats and uncertainties that are not addressed, and how they can affect the insights and conclusions.

VII. Make transparency a goal of model-based analysis. It is critical to make each model and resultant analysis as transparent as possible. Model source code and data should be publicly accessible in order to enable third party replication of results [6]. This is particularly true of analysis that supports decisions related to public policy. However, open models are not enough. Modelers must carefully document the model and input data as well as key assumptions and judgments made within each analysis. They should also provide guidance on how to interpret the results, given the relevant caveats.

\section{Steps associated with ESOM-based analysis}

The overarching guidelines articulated in Section 2 should be revisited throughout the model application process, which involves a number of steps, as shown in Figure 1. We note that the steps in the modelling process are not strictly sequential; they can be considered simultaneously and iteratively refined. Each step involves a number of considerations, which are described in Sections 3.1-3.6. At the end of each subsection, we provide summary guidance, and where appropriate, lay out critical challenges that must be met.

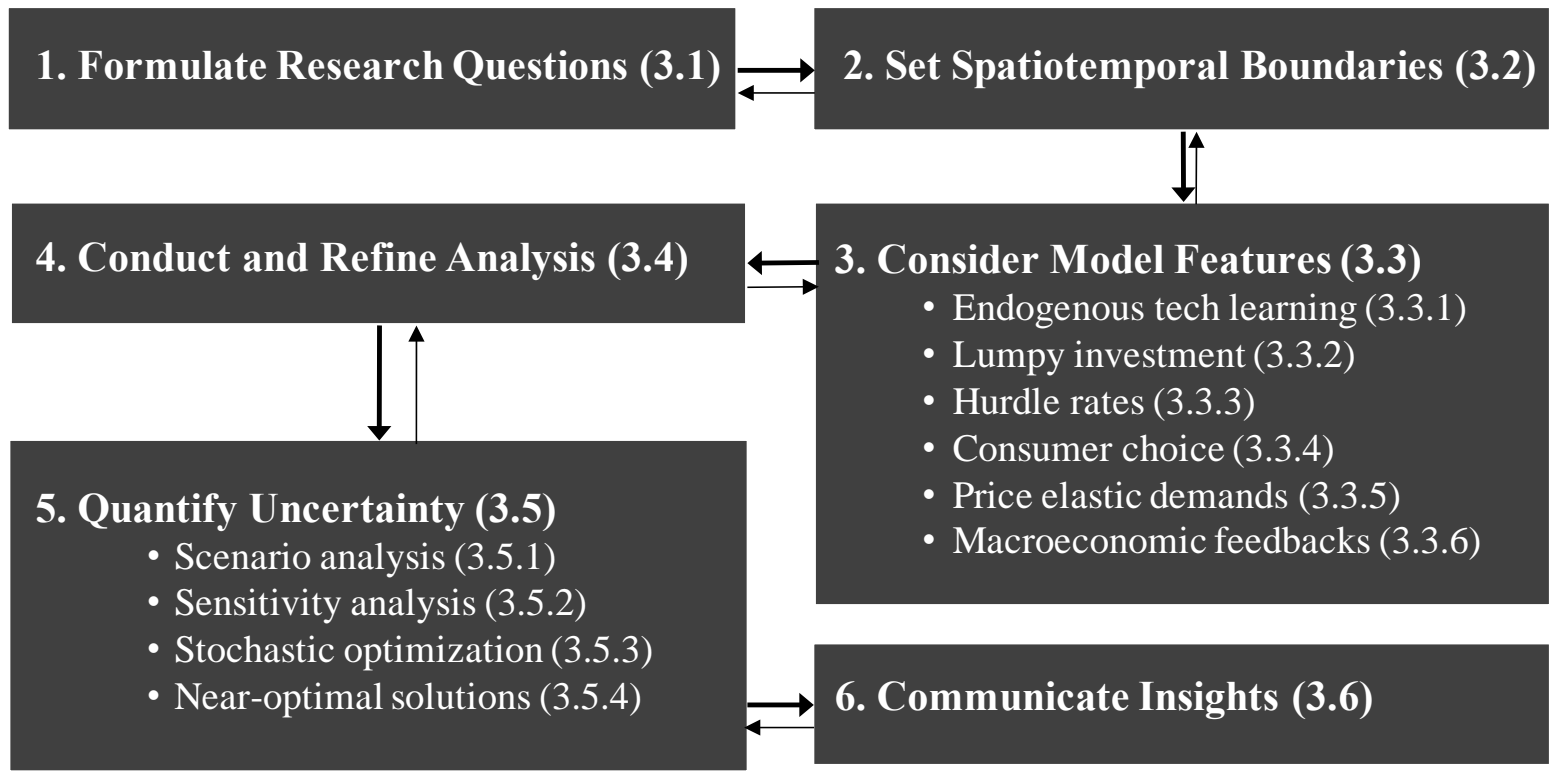

Fig. 1. Key steps associated with the application of ESOMs. The thinner arrows indicate that iterative refinement is part of the process. The numbers in parentheses indicate the section or subsection in which the associated step is discussed.

\subsection{Formulate research questions}

Much time is wasted conducting analysis without a clearly defined purpose [1]. Before running the model, it is imperative to formulate a specific set of research questions that map the issue at hand to appropriate modelling capabilities. To properly formulate questions, modelers must 
identify the target audience and the decisions to which the model-based analysis is trying to lend insight. It is also important to consider whether the model is being used to "project, provoke, postulate, or prospect" [30]. Broader issues of study design should also be considered along with the development of research questions. The goal and scope phase of life cycle assessment is instructive, and includes several elements that are also relevant to the first stage of energy system modelling: (1) define the goals of the project; (2) determine what type of information is needed to inform decision makers; (3) determine the required specificity in the results; (4) evaluate how data should be organized and results displayed; (5) define the scope of the study; and (6) determine ground rules for performing the work, including quality assurance and reporting requirements [31]. Time spent formulating clear and specific research questions that fit into a coherent study design lends clarity to all downstream analysis-related decisions.

Summary Guidance: Modelers should carefully formulate research questions while considering the underlying goals of the analysis and the intended audience. This process requires careful application of the first guiding principle. In addition, the modelling community should develop more formal guidance, using the goal and scope phase of life cycle assessment as a starting point.

\subsection{Set spatio-temporal boundaries}

Using the analysis-specific motivation and research questions as a guide, it is important to consider the necessary spatial and temporal boundaries for the proposed analysis. There is a tradeoff between model complexity and a realistic representation of spatiotemporal detail [32]. For example, models depicting systems with a potentially high share of variable renewables will require high spatiotemporal resolution compared to a fossil-based system. Table 1 presents a set of considerations that can be used to help guide the selection of appropriate spatio-temporal boundaries.

Table 1. Considerations associated with the selection of spatial (top) and temporal (bottom) boundaries associated with ESOM-based analysis

\begin{tabular}{|c|c|}
\hline \multicolumn{2}{|c|}{ Spatial considerations } \\
\hline $\begin{array}{l}\text { Sub-Regional Representation } \\
\text { - Tradable energy commodities } \\
\text { - Technology cost } \\
\text { - Demands } \\
\text { - Government policies } \\
\text { - Degree of urbanization } \\
\text { - Existing infrastructure } \\
\end{array}$ & $\begin{array}{c}\text { Rest-of-World Representation } \\
\text { - Policy regimes } \\
\text { - Technological learning } \\
\text { - Emissions pricing }\end{array}$ \\
\hline \multicolumn{2}{|c|}{$\begin{array}{r}\text { Temporal Considerations } \\
\end{array}$} \\
\hline $\begin{array}{l}\text { Sub-Annual Representation } \\
\text { - Demand profiles } \\
\text { - Variable renewable energy } \\
\text { - Energy storage }\end{array}$ & $\begin{array}{ll}\text { Time Horizon } \\
\text { - } \\
\text { - } \text { Capital stock turnover } \\
\text { - Myopia versus perfect foresight } \\
\text { - Growing uncertainty with time } \\
\text { - } \text { Consistency with policy timelines } \\
\end{array}$ \\
\hline
\end{tabular}


Using Table 1 as a guide, there are two key issues related to the selection of spatial boundaries within the ESOM: the sub-regional representation within the target area and the rest-of-world representation in relation to the target area. Selection of the target area itself is typically straightforward and follows directly from the motivation and research questions. Within the target area, the modeler must decide whether to explicitly model differences within sub-regions. Modelers should consider the following differences by sub-region: the price and availability of tradable energy commodities, such as natural gas or biomass; temporally-resolved resource availability; the cost of technology development and deployment; sub-regional demands that provide opportunities for more efficient resource sharing; government policies that reward resource and technology capacity sharing; and levels of urbanization and stocks of existing infrastructure, both of which may suggest varying sub-regional solutions. When deciding how to model the rest of the world (ROW) outside the target area, the same considerations for subregions apply. International policy regimes, emissions pricing, and global technology learning should also be considered since large uncertainties related to these factors can significantly affect the region(s) being modelled, and endogeneity exists in some variables between the modelled region and the rest of the world. Note that the number of decision variables in the model grows linearly with the number of regions, so regionalization can quickly increase the size of the input and output datasets.

With respect to temporal boundaries, modelers must consider both the model time horizon as well as the sub-annual representation. The time horizon represents the total timeframe under consideration. Generally, ESOM timeframes range from several decades to a century. The choice of time horizon should be long enough to observe the replacement of long-lived capital stock and maintain consistency with relevant policy timeframes. The choice of timeframe should be tempered by considering the incremental computational effort and the reality that results are subject to uncertainty that grows with time. In addition, the number and length of model time periods within an analysis should also be evaluated. It is common to use time periods that consist of 5- or 10-year segments, with each year within a time period assumed to produce identical results. Some models, such as TIMES and Temoa, allow time periods of varying length, so that modelers can specify shorter time periods in the near future when uncertainty is lower and longer model time periods in the mid- to long-term when uncertainty is higher and less temporal resolution is required.

ESOMs have perfect foresight, such that all future possibilities are known with certainty and the model simultaneously optimizes over the entire model time horizon. Some ESOM formulations allow for "myopic" runs whereby the model time horizon is split into a number of possibly overlapping time frames for which decisions are made sequentially, one model period at a time. As each time period is optimized, all considerations related to future time periods are ignored. A myopic approach can reflect the shorter timeframes associated with real world decision making. Myopic formulations have been developed for a limited number of ESOMs that usually assume perfect foresight (e.g., MESSAGE [33] and GET-LFL [34]), in addition to the models that rely on limited foresight in their standard formulation (e.g., IKARUS [35]).

ESOMs optimize a representative year within each time period, which is broken into sub-annual time segments that consist of combinations of different seasons and times-of-day. The subannual time slices allow the ESOM to capture finer resolution temporal variation in both 
resource supply and end-use demands. Many ESOMs use a limited number of time slices, which can become an issue when considering high penetrations of variable solar and wind energy [36]. Because ESOMs generally have a simplified temporal and geographical resolution [37], the representation of renewable energy resources is usually highly stylized [38]. In order to provide the necessary insights into transitioning to a low carbon system, an adequate representation of the spatial and temporal characteristics of renewables is needed [39-42].

Kannan [43] uses high resolution time slices within an ESOM to incorporate the impacts of intermittent renewables. Such an approach is able to better identify the need for flexible generation or energy storage than a low-resolution model, but does not have the ability to fully represent the variable nature of supply and demand in the same way as a high time resolution unit commitment and dispatch model [44]. When the driving research questions depend critically on an examination of renewable energy deployment, linking an ESOM to a unit commitment and dispatch model may give more robust insights than further temporal disaggregation within the ESOM itself [45-48].

Summary Guidance: Modelers should carefully consider Guiding Principles I and II when formulating spatio-temporal boundaries. The goal should be to formulate the boundaries with minimum complexity while still addressing the goals of the analysis. Table 1 outlines key issues to consider when setting spatio-temporal boundaries. Renewables exhibit significant spatiotemporal variability, and may therefore require a higher level of spatial and temporal disaggregation.

\subsection{Consider model features}

In its most basic form, an ESOM makes optimal technology investment and utilization decisions based on differences in the relative cost of competing technologies, thermodynamic performance limits, fixed end-use demands, and constraints that reflect known physical resource limits or policy objectives. The associated model-based results provide a prescription that indicates what should happen if a single rational economic decision maker acts from a social planning perspective to minimize cost. This perspective affects how the model outputs can be used to inform policy design, and as such, caution is required when interpreting results. For example, ESOM results can suggest massive shifts in technology market shares due to trivial differences in cost-performance $[4,49]$.

There are three fundamental omissions in the most basic ESOM formulations that lead to such simplified results. First, the models ignore the heterogeneity in decision making: decisions are taken by a range of actors, from supply-side investors to individual demand-side consumers, each with different preferences that modify their assumed cost-minimizing behavior. Second, ESOMs make technology deployment and utilization decisions based on exogenously specified differences in engineering-economic costs; they do not endogenously model the process of technology innovation or supply chain logistics that could accelerate or limit the rate of technology deployment. Third, basic ESOM formulations do not account for feedbacks between the macro-economy and energy systems, including the effect of energy commodity prices on demand or the feedback between broader macroeconomic conditions and energy demands. 
Modelers have developed an extensive toolkit in response to these three key limitations, as shown in Fig. 2. Conceptually, ESOM datasets can be divided into three subsystems. 'Supply' includes supply curves that capture the price-quantity relationships for specific commodities and processes that import, capture, or extract primary energy commodities. 'Intermediate conversion' represents technologies within the modeled energy system that transform primary energy commodities into intermediate, usable forms. Examples include uranium enrichment, electric power plants, and petroleum refineries. Finally, 'end-use' includes demand devices distributed across the commercial, industrial, residential, and transportation sectors that convert intermediate commodities into final, end-use demands. This model disaggregation provides a useful distinction, as not all model features apply equally throughout the energy system. In general, energy-related decisions in the end-use sectors tend to stray farthest from cost minimizing behavior.
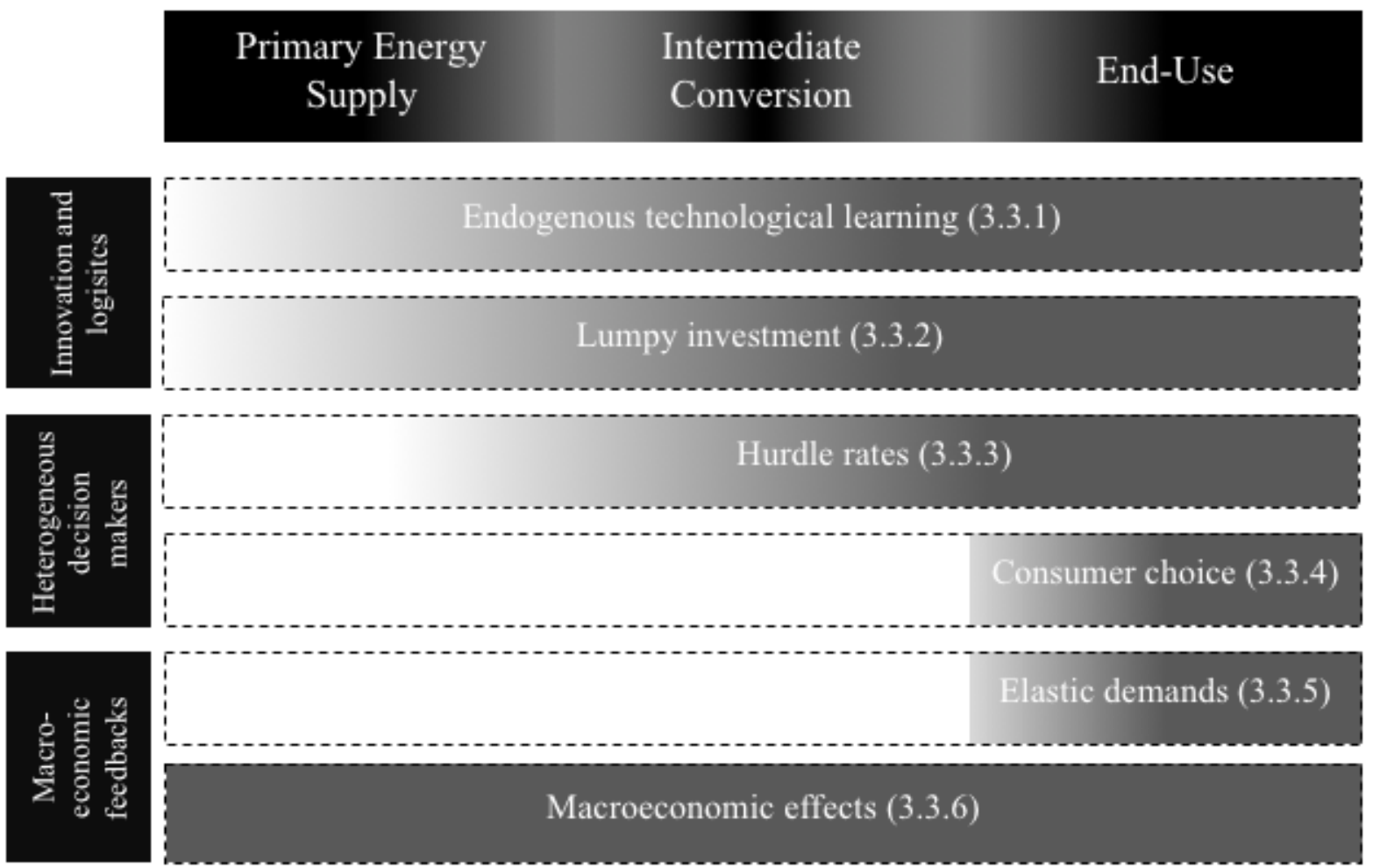

Fig. 2. A catalogue of ESOM features grouped by the challenge they are trying to address. To aid discussion, ESOM datasets are divided into three subsystems (primary energy supply, intermediate conversion, and end-use). Note that different model features apply to different subsystems, though the boundaries are fuzzy.

Sections 3.3.1 - 3.3.6 discuss the application of the model features outlined in Fig. 2 and provide guidelines for how they can be applied. Modelers must exercise judgment when evaluating the utility of these options for a specific analysis. The selection of features should be driven by the guiding principles articulated in Section 2. Most importantly, specific model features should only be utilized when absolutely necessary to address the problem at hand. Modelers must resist the temptation to employ model features simply because they are available. 


\subsubsection{Endogenous technological learning (ETL)}

Given the long time scales involved in energy system modelling, the effects of learning and innovation can have a large effect on the relative cost-effectiveness of different technologies. While technology costs are typically specified exogenously in ESOMs, endogenous technological learning (ETL) incorporates the effects of learning-by-doing on technology cost. More precisely, technology-specific investment costs are reduced by a specified learning rate each time the technology's cumulative capacity is doubled. ETL has been used widely in different energy system models (e.g., MESSAGE [50] and MARKAL [51]). A key benefit of ETL is that it produces internally consistent technology cost trajectories.

Several caveats related to the implementation and application of ETL should be noted. First, the modeled relationship between installed capacity and investment cost is non-linear and therefore binary variables are needed to implement ETL within a linear optimization model. Turning the model into a mixed integer linear programming model significantly increases the computational burden and thus ETL is typically applied to a subset of technologies. Since learning takes place with all technologies to some degree, modelers must ensure that ETL avoids learning asymmetries by applying it consistently and fairly across all relevant technologies within a given analysis. It is also possible to apply clustering, whereby learning is applied across a set of technologies that share similar components [51-53]. Second, ETL may be appropriate when a modelled country or region is driving technology innovation, but modelers need to keep in mind that ETL is a global phenomenon and modelers and policymakers need to be cautious in structuring the model and interpreting the results. Third, learning rates are non-trivial to measure $[54,55]$ and may not remain constant through time. While this same issue must be faced when making exogenous cost assumptions, the increasing returns to scale with ETL mean that very small changes in learning rate assumptions can lead to vastly different optimal investment portfolios. Fourth, the perfect foresight assumption means that the model can make massive investments in a single immature technology with a high learning rate without risk of failure. Fourth, investments in new capacity are in reality made by firms that - unlike the social planner

- would not necessarily see benefits in making a technology cheaper for other actors operating in the distant future. Thus the model results may suggest investment patterns that differ greatly from what one would expect to see in reality. Finally, because ETL requires a mixed integer formulation, shadow prices can no longer be used to represent marginal costs or equilibrium prices. The concept of an average shadow price has been developed for discrete optimization, but it is doubtful whether it can be used for all problem types and formulations [56].

Summary Guidance: ETL is a crucial tool that allows modelers to examine the effectiveness of technology-forcing policies. When research or policy efforts are aimed at driving innovation, failure to include ETL could undermine the ability of the model to assess the intended effects. Great care should be put into the interpretation of the results, however, as the model is not a prediction of the policy impacts, but merely an exercise depicting possible outcomes. In some cases, it may be more logical and transparent to specify changes in technology performance over time exogenously and then test through sensitivity analysis.

\subsubsection{Lumpy investment}

Most ESOMs are strictly linear models that can build continuous amounts of technology-specific capacity in any model time period. While this is a reasonable approximation for many 
technologies, in some cases it is appropriate to account for the granularity of investments by constraining the model to build discrete sizes of particular technologies, a method known colloquially as "lumpy investments." Lumpy investments require a mixed-integer formulation [15], and as with ETL, therefore take a longer time to solve.

Lumpy investments should be considered when only a small number of plants is likely to be built, such that a single plant would comprise a substantial part of the total capacity for that part of the energy system. For example, in a model of a city, a small country, or a large country with many regions specified separately, nuclear power plants could be specified using lumpy investments, while wind turbines would not as the capacity of a single turbine is comparatively small. Lumpy investments should also be considered where infrastructure cannot be constructed incrementally and is likely to have a low capacity factor in the early years of operation. For example, Dodds and McDowall [57] and Yang and Ogden [58] both use lumpy investments to represent the development of hydrogen transmission networks. On the other hand, electricity transmission networks already exist in many countries, so incremental capacity upgrades are typically represented without lumpy investments.

Summary Guidance: Lumpy investments are an important analytical tool when examining policies that can result in either a small number of plants constituting a significant fraction of total capacity, or when significant new infrastructure operating with low capacity factor in early years of operation are required. It increases computational time and therefore should only be used when necessary.

\subsubsection{Hurdle rates}

The base ESOM formulation assumes a social planner makes cost optimal decisions with perfect knowledge and access to capital. Hurdle rates represent technology-specific discount rates used to amortize investment costs over a technology's loan period or lifetime, and therefore adjust the relative sensitivity of the model's capacity installation decisions to investment costs. Hurdle rates can be used to represent the preferences of individuals or firms who require a different rate of return on an investment when considering non-economic borrowing costs such as time preference, risk, and uncertainty in their decision making.

Hurdle rates have a significant impact on investment decisions, abatement costs, and greenhouse gas emissions (e.g., [59-61]). For example, Kesicki [62] applied hurdle rates in different ways to the transportation sector and showed that baseline abatement pathways are not robust to different hurdle rate assumptions. This sensitivity creates a need for caution when applying, justifying, and communicating hurdle rates, which is done in widely different ways across studies. Hurdle rates can be derived empirically through stated- and revealed-preference studies, as in the case of barriers to energy efficiency investment. For example, the implicit discount rate for efficiency measures in the residential sector can range from $25 \%$ to $300 \%$ [61].

Specifying hurdle rates can be problematic given the lack of empirical evidence. The basis for these values often come from a few empirical observations of actual consumer purchase behaviors, such as those related to more efficient cars [63,64] or household appliances [65]. However, consumer preference is heterogeneous, differs across sectors and regions, and is highly uncertain in the future. Given the sensitivity of results to hurdle rates, transparency is key, but often lacking. Many ESOM studies do not state that hurdle rates are used, and of those that do, 
many fail to provide sufficient detail. The danger of applying and justifying hurdle rates without transparency is that they can be used as an opaque means of tweaking model results to yield a technology portfolio desired by the modeler.

Summary Guidance: Hurdle rates can be used to use to close the efficiency gap observed in the real world and produce a more realistic level of technology adoption when the lifetime cost of ownership associated with advanced demand technology is lower than conventional technology. However, modelers should carefully select hurdle rates that are specific to the investment decision at hand (e.g., energy efficient insulation, alternative vehicles, solar PV installation); the nature of the barrier (e.g., hidden costs, finance costs, lack of information, aversion to risk); and to whom the barrier applies (e.g., to a firm, individual, or government). It is also important to consider the quality of hurdle rate data across the entire dataset, else model results may be driven by a limited number of highly uncertain discount rates.

\subsubsection{Consumer choice}

As stated previously, consumer preferences and purchasing decisions are often poorly represented in ESOMs. Modelling methods that lack strong theoretical underpinnings and coherent empirical observations, such as hurdle rates, market share constraints, and technology growth rates have been frequently introduced to smooth out the projected technology adoption rates. These shortcomings have long been recognized and to some extent have limited the ability of ESOMs to produce more credible projections or policy evaluations.

Progress has been made in recent years to improve the behavioral realism of ESOMs. The most common approach is to create different consumer segments to represent the heterogeneity in consumer demand level and/or consumer choice [66-71]. Additionally, disutility costs have been introduced to represent perceived "non-market" costs such as value of time costs, risk attitudes, or market barriers [70]. For example, McCollum et al. [69] consider consumer behavior related to light duty vehicle purchasing in a global integrated assessment model and include the following disutility costs: refueling inconvenience cost, battery electric vehicle range limitation cost, vehicle model availability cost, risk premium, home charger installation cost, towing capability, and cargo space availability. Behavioral constraints, such as time budget constraints [68] and household budget constraints [66,67,71] have also been considered in some models. Bunch et al. [66] and Ramea [71] use a novel approach that combines a classic consumer choice model (nested multinomial logit discrete choice) [72,73], with an ESOM.

This recent work suggests the importance of understanding consumer behavior and consumer choice and developing methods to incorporate them into ESOMs. In general, these studies indicate that consumer investment decisions are often dominated by non-market costs, and highlight the significant heterogeneity in consumer demand and preferences. Modelers considering such methods should understand the theoretical basis of consumer preference and consumer choice [74] and ensure theoretical consistency when different methods are combined (e.g., cost minimization versus utility maximization [75]). There is also a great need for both more empirical observations and more proof-of-concept case studies like those mentioned above. Ultimately, predicting future consumer choice will remain challenging given the inherent difficulty in predicting rapid changes in technology attributes, the changing preferences of consumers, and the manner in which consumers adapt their behaviors toward new technologies. 
Nevertheless, an improved representation of consumer behavior and consumer choice can lead to insights regarding which policy levers, technology attributes, or market conditions may be the most conducive to accelerating the deployment of sustainable technologies that achieve the most socially optimal outcomes.

Summary Guidance: Adopting consumer choice methods within an ESOM can be useful to understand the types of barriers that exist for new technologies, and what kind of policies or technology breakthroughs are needed to lower these barriers and increase adoption. Some of the techniques discussed above have in fact changed the modelling paradigm by introducing consumer utility into a pure cost minimization model. Therefore, modelers should understand the theoretical basis of consumer preference and choice before applying within an ESOM. In order to refine the consideration of consumer choice in ESOMs, more empirical data and case studies are required.

\subsubsection{Price elastic demands}

Price elastic demands are a feature of ESOMs that allow for energy service demands to be responsive to changes in prices. First introduced in the MARKAL framework [76], this mechanism improves model representation of real world observations, where demand for energy decreases under price increases, and vice versa. This is modelled via linearized demand curves, which represent the change in each energy service demand as a function of the change in price for the energy service. Crucially, this mechanism means the ESOM is providing a partial equilibrium solution, where endogenous trade-offs are made between supply-side investment in technologies and fuels, including end use sector energy efficiency and conservation, and demand-side change in welfare gains or losses associated with changing demand.

The inclusion of elastic demands in a UK-focused model showed that price-induced demand response was particularly strong in those sectors with limited supply-side mitigation options [77]. Chen et al. [78] underline the importance of demand reduction in their analysis of mitigation costs in China, estimating a $60 \%$ reduction in marginal abatement costs in 2020 . Other analyses also support the importance of demand reductions in climate mitigation both in the UK [79] and globally [80].

While conceptually simple, the application of elastic demands in an ESOM present several datarelated challenges [81]. First, experience from the UK suggests that there are a wide range of estimated elasticities for the same service demands. For example, 10 of 13 estimated demand elasticities from Anandarajah et al. [77] are not contained within the ranges estimated by Pye et al. [81] for the same service demands. Second, it is imperative for the modeler to understand what elasticity estimates drawn from the literature represent, particularly whether the estimated elasticity is short-run or long-run, and whether the estimates correspond to changes in price and consumption associated with energy or service demands. It may be tempting to apply elasticities to all service demands, but in some cases the assumed demand elasticities lack an empirical basis and are only very rough proxies. For example, applying generic elasticities to industrial subsectors could overstate the role of specific subsectors that present limited technical opportunity for demand reduction. 
Further research is needed to better estimate maximum response levels; in addition, the impact of changes in energy services on one another should be assessed via cross-price elasticities. Careful consideration needs to be given to these elasticity factors, as they can strongly determine the model solution, particularly under stringent policy constraints, such as a carbon cap. Given the high uncertainty around many of these estimates, sensitivity analysis is recommended to understand how specific demand elasticities affect model outputs of interest.

Summary Guidance: Elastic demands are particularly useful when policy-induced price changes are expected to be large, anticipated price changes can have a significant effect on service demands, or the rebound effect and demand response are an important part of policy discussions. Modelers should use elasticity estimates consistently by ensuring that they are either short- or long-run and correspond to changes in either energy consumption or service demands. Modelers should be aware of differences in elasticity estimates both within and between sectors, and apply sensitivity analysis to ensure the robustness of insights relying on elastic demands.

\subsubsection{Macroeconomic feedbacks}

ESOMs with elastic demands are considered partial equilibrium because their scope is limited to the supply and demand balance of commodities modeled within the energy system. In some analyses; however, it is necessary to capture the economic effects of a perturbation beyond the boundaries of the energy system. In such cases, macroeconomic models, such as computable general equilibrium (CGE) models, can be employed to capture wider macroeconomic effects and capture the effect of changes in energy costs on the demand for energy services.

CGE models simulate the circular flow of commodities in a closed economy between households (which own the factors of production) and firms (which rent the factors of production from households to produce goods and services) [82]. Walrusian general equilibrium occurs when both product and economic value (i.e., expenditures and incomes) are balanced across all markets in the modeled economy [82]. The substitution among the factors of production (e.g., material, energy, labor) and consumption (e.g., material, leisure) are modeled explicitly. CGE models provide a data-consistent view of the entire economy, and enable the quantification of impacts associated with price and quantity distortions (e.g., taxes) across all markets of a given economy. Impacts include welfare losses, changes in gross domestic product, and pollution abatement costs that reflect macroeconomic adjustments. Capturing both the bottom-up technical detail in an ESOM with the top-down consistency in a CGE is an active area of ongoing research.

When an analysis requires general equilibrium considerations, there are three basic approaches: an ESOM linked to a simple economic module (e.g., [83]), a link between an ESOM and a complete CGE model (e.g., [84]), or the incorporation of technology detail into the energy sectors of a CGE model (e.g., [85]). A more complete introduction to hybrid modelling approaches is given by Hourcade et al. [12] and more recently by Glynn et al. [86], which discusses experiences of linking both national and global ESOMs to a variety of economic modules. Jacobsen [87] gives an overview of the types of models and issues involved in linking, including how variables can be aggregated to have an emphasis on top-down or bottom-up approaches. In addition, Gargiulo and Ó Gallachóir [11] outline several existing models, and draw distinctions between ESOMs and CGE models. 
There are several instances in which ESOMs have been combined with simple general equilibrium modules to incorporate both the effects of energy system changes on the aggregate economy and the economic feedback returning to the energy system. Hamilton et al. [83] outline the development of MARKAL-MACRO, which hard links MARKAL, a well-known ESOM, to a simple macroeconomic module. While the MACRO model maximizes the inter-temporal utility function of a single producer-consumer, there is only a single sector for each modeled region. More recently, Kypreos and Lehtila [88] have produced the Macro Stand-Alone (MSA) module hard-linked into the TIMES framework. The MSA model is a single agent; single sector, multiregional, general equilibrium optimal growth model which maximises the discounted utility of a single consumer-producer agent and can now be applied to multi-regional global models. The TIMES and MSA models are run iteratively until there is convergence in energy demands. However, a single sector simplification does not capture the inter-linkages and substitution possibilities of multi-sector models that allow for economy-wide results. Messner and Schrattenholzer [89] also discuss the similar MESSAGE-MACRO model, which is solved iteratively through a soft-link. In this case, supply curves derived from MESSAGE are fed into the two production sectors of MACRO (electric and non-electric), which then returns a set of demands into MESSAGE.

Summary Guidance: Linking an ESOM to a CGE model should only be considered when the study objectives require quantification of economic impacts beyond the energy system (e.g., GDP impacts). Linking the two model types requires careful consideration of data harmonization, such as GDP and emissions trajectories, in order to provide consistent results. Deciding which data should be transferred between the models is critical; at a minimum it will consist of changes in energy prices flowing from the ESOM to the top-down model, and changes in energy demands flowing in the opposite direction.

\subsection{Conduct and refine the analysis}

Once the model and input dataset are established, modelers conduct and refine the analysis. Calibration is a critical aspect of ESOM-based analysis, and represents an iterative process of refinement to ensure plausible results. The calibration process is guided by recent historical trends, projections by other models covering the same spatial and temporal domains, and the modeler's own understanding of the modeled energy system.

Model results deemed implausible can be addressed with a variety of common calibration techniques. For example, technology-specific bounds on capacity or activity can be applied to control technology deployment and utilization. In addition, growth rate constraints can be applied to specific technologies to prevent them from dominating new capacity installations. Likewise, market share constraints are often added to ensure that a certain technology is constrained to a minimum or maximum share within a given sector. These techniques are typically used throughout the energy system and the constraint specifications are refined through the calibration process. Calibration can also produce new insight that leads the modeler to reconsider the model features employed or the chosen spatiotemporal boundaries, emphasizing the iterative nature of ESOM-based analysis. 
Given the subjective judgment required, model calibration is also fraught with challenges. In its purest form, modelers employ rigorously derived empirical estimates to inform the constraint formulations. In such cases, the modeler is able to expand the model's knowledge claims further into the technological, economic, and human behavioral realms. However, modelers must exercise subjective judgment when adding such ad hoc constraints. The data required to develop constraint coefficients varies widely in quality and availability. Some input data, such as future market shares are often based on historical trends despite the recognition that structural changes in markets or technology breakthroughs can produce significant deviations from past trends. There is also a danger that modelers add constraints - with limited empirical basis - in order to make the model future conform to their mental model about how the future should unfold. In this case, the model is not making new claims on knowledge, but rather is simply reflecting the preconceived notions of the modelers. This phenomenon is well known: Keepin and Wynne [49] demonstrated that overly constrained models may simply return results that are prescribed a priori by the modeler through constraints. This problem can be exacerbated by perceived peer pressure, as most modelers prefer not to produce results that are widely divergent from their

peers. To overcome this challenge, modelers should be rigorous in their thinking and question every assumption. Modelers should take care to document the reasoning and empirical basis for user-defined model constraints. Such assumptions could be documented as internally consistent storylines, making them easier for the audience outside the modelling community to grasp and memorize [90].

While not a regular part of ESOM-based analysis, periodic verification checks of the model formulation should be performed. Particularly for new modelers, it is a valuable exercise to verify results from a simple ESOM test case through comparison with other ESOMs, spreadsheets, or even pen and paper calculations. For example, Hunter et al. [18] conducted a careful verification of Temoa by analyzing the same input dataset with MARKAL and found that the latter underinvests in demand device capacity in cases where the demand rate (e.g., PJ/year) varies throughout the year.

Summary Guidance: ESOMs and their associated input datasets require iterative refinement, which is accomplished through the calibration process. It is imperative that modelers exercise caution when adding constraints through the calibration process; otherwise, the results may simply reflect the preconceived notions of the modelers. All model and data refinements should be carefully documented and actively questioned.

\subsection{Quantify uncertainty}

The long-term future transition of the energy system is shaped by a combination of factors that are deeply uncertain, including technology innovation, resource availability, and socio-economic dynamics. Given such deep uncertainties about the future, singular ESOM projections obscure the full spectrum of possible energy system futures. The focus of ESOM-based analysis should thus be based on producing insights, which requires the identification of patterns across ESOM model runs under uncertainty.

Two types of uncertainties can be distinguished for ESOMs: parametric and structural [23,91]. Parametric uncertainty refers to imperfect knowledge of ESOM input values. Structural uncertainty refers to the imperfect mathematical relationships that govern energy system 
development and operation within the model. In this section, we describe several approaches for dealing with uncertainty in ESOMs that address both parametric and structural uncertainty.

\subsubsection{Scenario analysis}

A common approach that avoids the pitfalls associated with forecasting is scenario analysis, where each scenario corresponds to a storyline about how the future may unfold along with a set of exogenous assumptions consistent with the storyline that is used to drive the model. This method of combining quantitative and qualitative elements is sometimes referred to as a "storyline and simulation" approach [92], which can provide "a more qualitative and contextual description" [93]. All schools of scenario development seek to differentiate between scenario building and the purely mechanistic projection of historical trends [94-97]. Scenarios often include quantitative predictions, but by definition cannot be separated from their contextual framing [98]. Scenario analysis can be used to address parametric uncertainty by translating scenario assumptions into ESOM input parameters, and it can address structural uncertainty by altering the model formulation to address an uncertain scenario element.

In the early part of the 21 st century, some scholars suggested that scenario thinking suffered from a "lack of paradigms", comprised a range of "vastly different and even furiously conflicting" approaches and characterized the field as being in "methodological chaos" [99]. Commenting on the complexity of scenario development, researchers noted that "there is no single way of planning scenarios" [100] and that "almost every new scenario process... ultimately develops a virtually customized approach" [101]. Various attempts have been made to map the landscape of scenario planning techniques [102-106], and there is no shortage of literature offering suggestions for a prescriptive multi-stage process to design, build, evaluate and draw inferences from scenarios [95,107-110].

Scenarios can include narrative elements that are not formally modelled, enabling them to combine quantitative analysis and subjective interpretations [111]. However, as Morgan and Keith [2] point out, this can be a pitfall as well as a strength: scenarios with detailed storylines can play into cognitive biases by appearing more plausible and probable than they are in reality. Another limitation of scenario analysis is that mutually exclusive and exhaustive subjective probabilities are often not assigned to scenarios, leaving decision makers with a disparate set of energy futures to ponder $[2,112,113]$, though not all agree about the appropriateness of assigning probabilities to scenarios [114]. Finally, traditional scenario analysis can be effective with small groups of clients whose concerns are well known to the scenario developers, but can fail to generate consensus in broad public debates that include divergent interests and values $[115,116]$. Despite these limitations, scenario analysis can be a valuable tool to explore energy futures.

Summary Guidance: For non-market-based policy instruments, such as targets, standards, or regulations, scenario analysis is one the simplest ways to explore the decision landscape under alternative futures. Modelers should strongly consider the methodological heritage of various scenario approaches, ensure consistency among scenario assumptions, and carefully consider the limitations and caveats associated with the analysis while drawing insights. 


\subsubsection{Global sensitivity analysis}

Global sensitivity analysis is typically used to address parametric uncertainty by identifying the model input parameters that have the largest influence on the modelling results. Such analyses can be conducted for a single parameter at a time or for combinations of input parameters, which may be correlated. Global sensitivity analysis can be employed to simultaneously vary many input parameters based on predefined probability distributions or plausible ranges. The results of applying global sensitivity analysis to an ESOM can provide a ranking of inputs by importance, yield insight into the specific combinations of parameters that lead to outcomes of interest, identify the input parameters that drive model results, and screen out unimportant parameters from a scenario analysis (e.g., [4],[117]). These insights can be used to better define the scenarios under which the ESOM is run, ensuring that the scenarios cover important areas of the input parameter space.

Sensitivity analysis can also be used to test structural uncertainties. Alternative model formulations (e.g., with or without elastic demand) can be used to understand the sensitivity of model results to these variations in model formulation, in the context of both structural and parametric uncertainty. Sensitivity analysis applied in this way can help extract insights that are robust to different model formulations and help navigate the catalogue of ESOM features (Fig. 2) in a structured way. In addition, multi-model exercises that explore the same future scenarios can be used to identify structural uncertainties across models (e.g., [118]).

Summary Guidance: Market-based policy instruments rely on robust policy designs under uncertainty. Global sensitivity analysis should be applied wherever possible to test the robustness of model results and insights. Sensitivity analysis can help determine whether a single input parameter value, combination of parameter values, or a structural assumption built into the model are driving the results and help focus scenario analyses.

\subsubsection{Stochastic optimization}

A limitation of ESOMs is that an individual scenario assumes all uncertainty is resolved ex ante: all parameters are assigned values prior to the model run. However, decision makers need to take action before uncertainty is resolved. Stochastic optimization can address this limitation by explicitly considering uncertainty within the model formulation. A stochastic ESOM encodes uncertain future outcomes within an event tree, where each branch in the tree is assigned an outcome and an associated probability. Optimizing over a finite set of future outcomes encoded within the event tree yields a near-term hedging strategy that accounts for potential future outcomes and puts the decision maker in a position to take recourse action as uncertainty is resolved. Several applications of stochastic optimization using an ESOM have been conducted (e.g., [119-125]).

A key challenge related to stochastic optimization is the curse of dimensionality: the number of decision variables grows exponentially with the number of uncertain parameters and the number of uncertain time stages. As a result, applications with stochastic optimization involve a limited number of possible outcomes, typically with event trees that include less than eight scenarios across two time stages. It is possible to take advantage of high performance computing resources coupled with decomposition techniques that make use of parallel computing in order to expand the size of the event tree. For example, progressive hedging algorithm decomposes a stochastic 
problem into a set of paths through the event tree that can be solved using parallel computing resources [126]. In addition, sampling-based decomposition algorithms can be used to approximately solve problems $[127,128]$.

While more advanced optimization techniques can expand the size of modeled event trees, the large number of uncertainties mean that the curse of dimensionality will always exert its influence. An additional limitation of stochastic optimization is that it only deals with parametric uncertainty. Thus, while stochastic optimization can yield a hedging strategy, it is only robust to variation in a limited number of parameter values and not broader uncertainties related to model structure.

Summary Guidance: Stochastic optimization should be considered when the goal is to explore optimal near-term planning strategies that hedge against future uncertainty. The curse of dimensionality limits the number of uncertain parameters that can be included, so modelers should also consider uncertainty that is omitted from the event tree.

\subsubsection{Generating near-optimal solutions}

Since ESOMs are linear programming models, it is possible to modify the model formulation in order to explore alternative solutions that are near optimal in solution space but very different in decision space. In an ESOM context, this means finding alternative solutions that are close to the minimum cost or maximum welfare but utilize a different set of technologies to meet end-use demands.

A technique called 'modelling to generate alternatives' (MGA) was developed and applied to examine water and land management problems in order to produce a set of alternatives for planners to consider $[129,130]$. This technique involves several steps. First, a base case version of the optimization is solved. Second, the objective function is encoded as a constraint, and the optimal objective value from the base case run along with some added slack is encoded as the right hand side of this new constraint. The slack value determines the flexibility afforded to the model while seeking alternative solutions. Third, a new objective function is formulated, which minimizes the non-zero decision variables from the base solution. Fourth, the reformulated model is iterated, where each iteration includes an updated objective function that includes all decision variables with non-zero values from all previous iterations. Fifth, the algorithm is terminated after a set number of iterations or the solutions begin to repeat themselves.

DeCarolis [131] presented the application of MGA to a simple energy portfolio, and DeCarolis et al. [132] applied MGA to an ESOM in order to explore different ways to weight the MGA objective function. Trutnevyte [133] incorporated MGA to better evaluate the economic potential of renewable energy. In addition, Trutnevyte [4] used MGA to model cost-optimal and nearoptimal electricity supply scenarios using empirically estimated slack from a retrospective modelling exercise. Price [134] has developed a formulation of the MGA objective function that maximizes the difference associated with the consumption of each primary energy commodity between successive MGA iterations. Most recently, Li and Trutnevyte [135] combined Monte Carlo simulation with MGA to produce 800 different scenario pathways in order to explore UK electric sector transition pathways to 2050 . 
The application of MGA represents a simple way to explore structural uncertainties in the model. No optimization can fully capture real world complexity; unmodeled objectives and constraints are always present. Thus, decision makers may find that the near optimal solutions are preferable to the base solution when their own preferences and concerns - exogenous to the model - are brought to bear on the model solutions. Unlike stochastic optimization, which explicitly incorporates uncertainty into a single run to help inform a decision strategy, MGA yields a set of computer-generated alternatives. The intent of MGA is not to provide a singular answer, but rather to provide a set of alternative solutions that indicate the degree of flexibility in the model solution and can be further evaluated.

Summary Guidance: Because MGA can produce alternative solutions that perform well with regard to the modelled objective but are very different in decision space, it should be considered when analysts or decision makers wish to consider a wide range of alternatives. MGA can also be used to test the flexibility of the base solution within a user-specified cost range.

\subsection{Communicate insights}

The goal of effective communication is to help policymakers and others decision makers to draw appropriate insights from the work and to understand their significance in light of the limitations of the modelling framework. With tools that generate what can appear to be precise long term forecasts, there is a risk that either policymakers will draw incorrect conclusions from modelling work, or as noted by Craig et al. [1], that model outputs will be used simply to provide scientific justification for decisions made for other reasons.

Scholars have emphasized the importance of various aspects of communication, in particular, focusing on 'insights' rather than precise numerical outputs $[7,136]$; transparency of input data, model structure and outputs [17,18]; involvement of decision makers in an iterative modelling process [91]; and provision of adequate information about the uncertainties associated with the results [137]. Each is described in turn below.

Model results must be synthesized into insights before presentation to decision makers. Given the limitations of ESOMs and models more generally, policy-relevant conclusions can rarely be drawn by inspection of model results alone. Insight is generated by examining the model results while considering the key uncertainties, model limitations, and spatiotemporal boundaries of the analysis. Modelers should present the key results; there is often a tendency to include too many results which can mask or muddle the key insights. When presenting caveats to decision makers, Kloprogge et al. [137] suggest it is best to avoid ambiguous statements such as 'care should be taken in interpreting these results' since people fit evidence to their existing beliefs, an effect known as 'confirmation bias.' General caveats may either be ignored by those who agree with the findings or provide an invitation to discredit the analysis by those who disagree with the findings. Clearly focused caveats, on the other hand, can reduce the tendency for biased interpretation.

Transparency is routinely identified as an important criterion for responsible and appropriate use of modelling to support decision-making and policy development $[1,6,138]$. Published documentation as well as open source code and data provide a strong basis for those with the relevant skills and knowledge to interrogate key assumptions and reproduce relevant findings. 
However, in the context of models as complex and data-rich as ESOMs, transparency is not a straightforward goal to achieve, since deep modelling knowledge is often required to understand the relative importance of different assumptions. Transparency is thus an ongoing process of explanation and engagement, alongside open data and model information.

To maximize the relevance of an ESOM-based modelling exercise to decision makers, they should be involved throughout the analysis. Lempert et al. [91] emphasize the importance of engaging stakeholders early to avoid disconnects between the final analysis with neatly drawn system boundaries and real world policy debates, which must typically address a wider range of complex, non-technical issues. For example, early involvement of decision makers can help link modelling outcomes with policy-specific assessment criteria. In addition, engagement with the public on energy issues can reflect "useful social intelligence" back to scientists, engineers, and decision makers, which can also inform the approach to model-based analysis [139]. One way to engage stakeholders is through the use of decision aids, which can distill complex issues into a simplified decision framework. For example, Pidgeon et al. [139] used a tool developed by the UK's Department of Energy and Climate Change to engage the UK public on issues related to national energy planning. ESOM-based analysis could be used to develop such energy-related decision aids to help engage a broad range of stakeholders. The effectiveness of such tools should be evaluated with formal procedures [140].

It is widely agreed that effective communication of results must include adequate attention to communication of uncertainties [138,141]. Ideally, this should address both structural and parametric uncertainty, and with the latter, information about which parameters are most sensitive [141]. Kloprogge et al. [137] provide a valuable guide for the communication of uncertainties to policy audiences, drawing on the literature that links heuristics and biases to human judgment and decision-making. They articulate a framework for the "progressive disclosure of information," which highlights that attention must be paid to reporting the right kind of information in the right place. In particular, the 'outer' layers of reports, such as the executive summary and conclusions, should contain information appropriate to wider audiences and more general messages, including top-level information on uncertainties and levels of confidence along with headline conclusions. More detailed and technical issues can be described in the "inner layers," represented by the main body of the report and in the technical appendices. They also note the importance of "framing biases," whereby the interpretation will depend on where uncertainty is conveyed: uncertainties presented as footnotes or alongside more detailed technical information will tend to be understood as less important than those presented upfront alongside key messages.

Summary Guidance: Analysis aimed at informing decision makers should involve them from the outset of the project. Modelers should aim for transparency through open source code and data, well-written documentation, and selective use of ESOM features to avoid unnecessary complication. Reports should focus on communicating robust insights rather than singular projections. Caveats should be communicated, but modelers should avoid vague statements that unintentionally call into question the study findings. Future uncertainty should be adequately addressed, using the methods described in Section 3.5. 


\section{Application of ESOM Best Practice in the UK}

The UK experience with ESOMs over the last decade is highly illustrative of the application of best practice described herein. Similar to other countries, ESOMs have a long track record of academic and policy use in the UK [142], but came into sharp prominence when the UK became the first major economy to legislate long-term greenhouse emission targets [143]. The policy process to implement near- and long-term measures to meet these targets [144] heavily utilized ESOMs, whose techno-economic viewpoint became the policy lens for much of the decarbonisation debate in the UK [145]. This is not to say that the use of ESOMs in the UK is exemplary - far from it - but rather that in terms of the available modelling capacity [146], and the mismatch between policy maker, research funding, and energy model development cycles [147], policy and industrial decision makers used ESOMs as the most appropriate available tool, and wrestled with implementing the best practice steps shown in Figure 1.

The formulation of research questions (Step 1) was largely driven by the overall energy decarbonisation policy debate, and centered around elucidating pathways to the overall targets [148], linking climate mitigation and other energy policy goals (e.g, renewable support [79]), and the assessment of specific resource/technology options (e.g., [149]). As the dominant features of a low cost mitigation strategy began to emerge, such as the early decarbonisation of electricity or the robust benefit of building energy efficiency and demand reduction [81], policy interest and ESOM insights became part of an iterative process of inquiry [150]. This was exemplified in the constant trade-off between model research focus and model complexity in the evolutionary development of ESOMs models [28].

The UK policy focus on national decarbonisation strategies determined the spatiotemporal boundaries (Step 2). International drivers [151] were treated exogenously via sensitivity or scenario analysis [104]. A greater temporal resolution required linkage to a more detailed power system model [152]. Furthermore, the evolutionary development of the policy-modelling interface is seen clearly in the development and use of specific model features (Step 3). This was in part facilitated by the flexibility of ESOMs to be quickly adapted to include new features or to be linked with another energy model in order to create a hybrid tool. Examples include endogenous technological learning [52], demand hurdle rates and consumer choice [81], macroeconomic implications [153], and embedded and lifecycle emissions [154].

The policy-modelling interface comes full circle when conducting and refining the analysis (Step 4). The process included a reassessment of how mitigation pathways are compared to a business as usual case [146], an evaluation of fragility associated with mitigation pathways [155], and the ex-post assessment of ESOM outputs [4]. A major weakness in the UK experience was in the lack of replicability and full transparency of such complex modelling tools [6].

The UK experience included a major push to quantify uncertainty (Step 5) as illustrated by the extensive analysis underpinning the development of decarbonisation pathways (e,g., [143]). This included scenario analysis [104], global sensitivity analysis [117] and stochastic optimization [156].

Finally and critically, the communication of ESOM-based insights (Step 6) has been an ongoing focus of this academic research effort. Model-based analysis has underpinned technical 
appendices to landmark UK government policy reports on the target setting [143], implementation [144], and ongoing assessment [157] of the carbon budget approach to the UK's long-term energy decarbonisation pathways. This has been further facilitated by the creation of an expert ESOM user group consisting of technical policy staff across all major decision making bodies within and advising the UK government [146]. The ongoing challenge is to broaden the communication of ESOM insights to wider stakeholders, through an open source modelling process and interface [147].

\section{Conclusions}

The application of ESOMs to draw policy-relevant insight regarding future energy system development and associated environmental impacts is fraught with challenges. The models have expansive spatial and temporal boundaries, the formulations are highly simplified given the complex dynamics that govern real world energy systems, and model projections cannot be validated through comparison to actual outcomes. Operating under such challenging circumstances requires modelers to exercise careful judgment. These challenges notwithstanding, ESOMs are a critical tool employed by government agencies to develop energy planning strategies. For example, participating nations need to develop long-term greenhouse gas mitigation strategies under Article 4.19 of the Paris Accord [158], and ESOMs will surely play a role.

Despite the use of ESOMs to produce high visibility assessments, there has been little attempt to formalize the approach to model-based analysis. By contrast, life cycle assessment (LCA), which involves similar analyst judgments, has benefitted from efforts aimed at a standardization in approach (e.g., [29,31,159]). While such guides belie the ongoing methodological debates within the LCA community [160], they have produced consensus on a broad range of issues and serve as a practical guide for LCA practitioners. While the application of ESOMs has had significant influence on public policy [19], there has been little effort to develop formal, general guidance related to their application. Sound modelling practice is now typically learned through apprenticeship with more experienced modelers.

This paper is the first effort to document and formalize best practice regarding the application of ESOMs. We view such modelling guidelines as an important community resource. Guidelines create a set of expectations for ESOM-based analysis and help to standardize the approach to model application. They also serve as a guidepost for decision makers who rely on the insights from ESOMs to inform policy. In addition, the existence of guidelines, however imperfect, also serve as a baseline for future debates and methodological refinements.

The model features and uncertainty techniques listed in this paper have evolved through the application of ESOMs to the energy policy landscape over the previous 30 years, and the guidelines in this paper draw upon first-hand experience and the body of ESOM literature. As the energy sector continues to develop, perhaps moving towards a system based on low carbon or distributed energy sources, smart systems, and increasingly integrated with other complex infrastructure systems, it is likely that new tools and modelling approaches will need to be developed to tackle the novel research challenges that arise. As such, we expect that best 
practice guidelines will evolve over time as more people participate in the discussion, models and data are refined, and the decision landscape changes.

\section{Acknowledgements}

The first author was supported through a fellowship offered by the EPSRC funded Whole Systems Energy Modelling consortium (wholeSEM; Grant No. EP/K039326/1), as well as National Science Foundation Grant No. 1055622.

\section{References}

[1] Craig PP, Gadgil A, Koomey, Jonathan G. What Can History Teach Us? A Retrospective Examination of Long-Term Energy Forecasts for the United States. Annu Rev Energy Environ 2002;27:83-118.

[2] Morgan MG, Keith DW. Improving the way we think about projecting future energy use and emissions of carbon dioxide. Climatic Change 2008;90:189-215. doi:10.1007/s10584008-9458-1.

[3] Smil V. Perils of Long-Range Energy Forecasting: Reflections on Looking Far Ahead. Technology Forecasting and Social Change 2000;65:251-64.

[4] Trutnevyte E. Does cost optimization approximate the real-world energy transition? Energy 2016;106:182-93. doi:10.1016/j.energy.2016.03.038.

[5] Betz G. What's the Worst Case? The Methodology of Possibilistic Prediction. Analyse \& Kritik 2016;32:87-106. doi:10.1515/auk-2010-0105.

[6] DeCarolis J, Hunter K, Sreepathi S. The case for repeatable analysis with energy economy optimization models. Energy Economics 2012;34:1845-1853.

[7] Huntington HG, Weyant JP, Sweeney JL. Modeling for insights, not numbers: the experiences of the energy modeling forum. Omega 1982;10:449-62. doi:10.1016/03050483(82)90002-0.

[8] John P. Weyant. A perspective on integrated assessment: An editorial comment. Climatic Change 2009;95:317-23.

[9] Peace J, Weyant, John P. Insights Not Numbers: The Appropriate Use of Economic Models 2008.

[10] Häfele W, Rogner H-H. A Technical Appraisal of the IIASA Energy Scenarios? A Rebuttal. Policy Sciences 1984;17:341-65.

[11] Gargiulo M, Gallachóir BÓ. Long-term energy models: Principles, characteristics, focus, and limitations. WENE 2013;2:158-77. doi:10.1002/wene.62.

[12] Hourcade J-C, Jaccard M, Bataille C, Ghersi F. Hybrid Modeling: New Answers to Old Challenges Introduction to the Special Issue of The Energy Journal. Energy Journal 2006;27:1-11.

[13] Pye S, Sabio N, Strachan N. UKERC Energy Strategy Under Uncertainties An Integrated Systematic Analysis of Uncertainties in UK Energy Transition Pathways 2014.

[14] Loulou R, Remme U, Kanudia A, Lehtila A, Goldstein G. Documentation for the TIMES Model: PART I 2005.

[15] Loulou R, Goldstein G, Noble K. Documentation for the MARKAL Family of Models 2004. 
[16] Messner S, Strubegger M. User's Guide for MESSAGE III. Laxenburg, Austra: International Institute for Applied Systems Analysis; 1995.

[17] Howells M, Rogner H, Strachan N, Heaps C, Huntington H, Kypreos S, et al. OSeMOSYS: The Open Source Energy Modeling System: An introduction to its ethos, structure and development. Energy Policy 2011;39:5850-70. doi:10.1016/j.enpol.2011.06.033.

[18] Hunter K, Sreepathi S, DeCarolis JF. Modeling for insight using Tools for Energy Model Optimization and Analysis (Temoa). Energy Economics 2013;40:339-49. doi:10.1016/j.eneco.2013.07.014.

[19] Giannakidis G, Labriet M, Ó Gallachóir B, Tosato G, editors. Informing Energy and Climate Policies Using Energy Systems Models. vol. 30. Cham: Springer International Publishing; 2015.

[20] García-Gusano D, Espegren K, Lind A, Kirkengen M. The role of the discount rates in energy systems optimisation models. Renewable and Sustainable Energy Reviews 2016;59:56-72. doi:10.1016/j.rser.2015.12.359.

[21] Mundaca L, Neij L, Worrell E, McNeil M. Evaluating Energy Efficiency Policies with Energy-Economy Models. Annual Review of Environment and Resources 2010;35:30544. doi:10.1146/annurev-environ-052810-164840.

[22] Pfenninger S, Hawkes A, Keirstead J. Energy systems modeling for twenty-first century energy challenges. Renewable and Sustainable Energy Reviews 2014;33:74-86. doi:10.1016/j.rser.2014.02.003.

[23] Morgan G, Henrion M. Uncertainty. Cambridge University Press; 1992.

[24] HM Treasury. The Aqua Book: guidance on producing quality analysis for government. London, England, UK: HM Treasury; 2015.

[25] Funtowicz SO, Ravetz JR. Science for Policy: Uncertainty and Quality. Uncertainty and Quality in Science for Policy, Springer Netherlands; 1990, p. 7-16. doi:10.1007/978-94009-0621-1_3.

[26] Ciroth A, Muller S, Weidema B, Lesage P. Empirically based uncertainty factors for the pedigree matrix in ecoinvent. Int J Life Cycle Assess 2013:1-11. doi:10.1007/s11367-0130670-5.

[27] Dodds PE. Integrating housing stock and energy system models as a strategy to improve heat decarbonisation assessments. Applied Energy 2014;132:358-69. doi:10.1016/j.apenergy.2014.06.079.

[28] Dodds PE, Keppo I, Strachan N. Characterising the Evolution of Energy System Models Using Model Archaeology. Environ Model Assess 2014:1-20. doi:10.1007/s10666-0149417-3.

[29] European Commission. International Reference Life Cycle Data System (ILCD) Handbook - General guide for Life Cycle Assessment - Detailed guidance. Luxembourg: European Commission, Joint Research Centre, Institute for Environment and Sustainability; 2010.

[30] Howells M. Supporting Policy Coherence - Challenges and Successes in Extending Energy Systems Models to other Resources 2015.

[31] SAIC. Life Cycle Assessment: Principles and Practice. Reston, VA: US Environmental Protection Agency; 2006. 
[32] Sullivan P, Krey V, Riahi K. Impacts of considering electric sector variability and reliability in the MESSAGE model. Energy Strategy Reviews 2013;1:157-63. doi:10.1016/j.esr.2013.01.001.

[33] Keppo I, Strubegger M. Short term decisions for long term problems - The effect of foresight on model based energy systems analysis. Energy 2010;35:2033-42. doi:10.1016/j.energy.2010.01.019.

[34] Hedenus F, Azar C, Lindgren K. Induced Technological Change in a Limited Foresight Optimization Model. The Energy Journal 2006;SI2006. doi:10.5547/ISSN0195-6574-EJVolSI2006-NoSI1-4.

[35] Martinsen D, Krey V, Markewitz P. Implications of high energy prices for energy system and emissions - The response from an energy model for Germany. Energy Policy 2007;35:4504-15. doi:10.1016/j.enpol.2007.03.003.

[36] Chiodi A, Giannakidis G, Labriet M, Gallachóir BÓ, Tosato G. Introduction: Energy Systems Modelling for Decision-Making. In: Giannakidis G, Labriet M, Gallachóir BÓ, Tosato G, editors. Informing Energy and Climate Policies Using Energy Systems Models, Springer International Publishing; 2015, p. 1-12. doi:10.1007/978-3-319-16540-0_1.

[37] Simoes S, Zeyringer M, Mayr D, Huld T, Nijs W, Schmidt J. Impact of different levels of geographical disaggregation of wind and PV electricity generation in large energy system models: a case study for Austria. Renewable Energy 2015.

[38] Ludig S, Haller M, Schmid E, Bauer N. Fluctuating renewables in a long-term climate change mitigation strategy. Energy 2011;36:6674-85. doi:10.1016/j.energy.2011.08.021.

[39] Gass V, Schmidt J, Strauss F, Schmid E. Assessing the economic wind power potential in Austria. Energy Policy 2013;53:323-30. doi:10.1016/j.enpol.2012.10.079.

[40] Haller M, Ludig S, Bauer N. Decarbonization scenarios for the EU and MENA power system: Considering spatial distribution and short term dynamics of renewable generation. Energy Policy 2012;47:282-90. doi:10.1016/j.enpol.2012.04.069.

[41] Simoes S, Zeyringer M, Huld T, Schmidt J, Mayr D. The impact of location on competitiveness of wind and PV electricity generation - Case study for Austria. 2013 10th International Conference on the European Energy Market (EEM), 2013, p. 1-6. doi:10.1109/EEM.2013.6607406.

[42] Zeyringer MT, Daly H, Fais B, Sharp E, Strachan N. Spatially and Temporally Explicit Energy System Modelling to Support the Transition to a Low Carbon Energy Infrastructure - Case Study for Wind Energy in the UK. International Symposium for Next Generation Infrastructure Conference Proceedings: 30 September - 1 October 2014 International Institute of Applied Systems Analysis (IIASA),Schloss Laxenburg, Vienna, Austria 2015. http://www.ucl.ac.uk/steapp/isngi/proceedings (accessed July 2, 2016).

[43] Kannan R. The development and application of a temporal MARKAL energy system model using flexible time slicing. Applied Energy 2011;88:2261-72. doi:10.1016/j.apenergy.2010.12.066.

[44] Kannan R, Turton H, Panos E. Methodological Significance of Temporal Granularity in Energy-Economic Models_-Insights from the MARKAL/TIMES Framework. In: Giannakidis G, Labriet M, Gallachóir BÓ, Tosato G, editors. Informing Energy and Climate Policies Using Energy Systems Models, Springer International Publishing; 2015, p. 185-200. doi:10.1007/978-3-319-16540-0_11.

[45] Deane JP, Chiodi A, Gargiulo M, Ó Gallachóir BP. Soft-linking of a power systems model to an energy systems model. Energy 2012;42:303-12. doi:10.1016/j.energy.2012.03.052. 
[46] Pina A, Silva CA, Ferrão P. High-resolution modeling framework for planning electricity systems with high penetration of renewables. Applied Energy 2013;112:215-23. doi:10.1016/j.apenergy.2013.05.074.

[47] Welsch M, Deane P, Howells M, Ó Gallachóir B, Rogan F, Bazilian M, et al. Incorporating flexibility requirements into long-term energy system models - A case study on high levels of renewable electricity penetration in Ireland. Applied Energy 2014;135:600-15. doi:10.1016/j.apenergy.2014.08.072.

[48] Welsch M, Howells M, Bazilian M, DeCarolis, JF, Hermann, S, Rogner, HH. Modelling elements of Smart Grids - Enhancing the OSeMOSYS (Open Source Energy Modelling System) code. Energy 2012;46:337-50.

[49] Keepin B, Wynne B. Technical analysis of IIASA energy scenarios. Nature 1984;312:691-5. doi:10.1038/312691a0.

[50] Messner S. Endogenized technological learning in an energy systems model. J Evol Econ 1997;7:291-313. doi:10.1007/s001910050045.

[51] Seebregts A, Kram T, Schaeffer GJ, Bos A. Endogenous learning and technology clustering: analysis with MARKAL model of the Western European energy system. International Journal of Global Energy Issues 2000;14:289-319. doi:10.1504/IJGEI.2000.004430.

[52] Anandarajah G, McDowall W, Ekins P. Decarbonising road transport with hydrogen and electricity: Long term global technology learning scenarios. International Journal of Hydrogen Energy 2013;38:3419-32. doi:10.1016/j.ijhydene.2012.12.110.

[53] Anandarajah G, McDowall W. Multi-cluster Technology Learning in TIMES: A Transport Sector Case Study with TIAM-UCL. In: Giannakidis G, Labriet M, Gallachóir BÓ, Tosato G, editors. Informing Energy and Climate Policies Using Energy Systems Models, Springer International Publishing; 2015, p. 261-78. doi:10.1007/978-3-319-16540-0_15.

[54] McDonald A, Schrattenholzer L. Learning rates for energy technologies. Energy Policy 2001;29:255-61. doi:10.1016/S0301-4215(00)00122-1.

[55] Rubin ES, Azevedo IML, Jaramillo P, Yeh S. A review of learning rates for electricity supply technologies. Energy Policy 2015;86:198-218. doi:10.1016/j.enpol.2015.06.011.

[56] Liao G-L, Chen YH, Sheu S-H. Optimal economic production quantity policy for imperfect process with imperfect repair and maintenance. European Journal of Operational Research 2009;195:348-57. doi:10.1016/j.ejor.2008.01.004.

[57] Dodds PE, McDowall W. Methodologies for representing the road transport sector in energy system models. International Journal of Hydrogen Energy 2014;39:2345-58. doi:10.1016/j.ijhydene.2013.11.021.

[58] Yang C, Ogden JM. Renewable and low carbon hydrogen for California - Modeling the long term evolution of fuel infrastructure using a quasi-spatial TIMES model. International Journal of Hydrogen Energy 2013;38:4250-65. doi:10.1016/j.ijhydene.2013.01.195.

[59] Daly H. How we treat behaviour in energy system optimisation models 2015.

[60] Grohnheit PE. Impact of technology and regional specific discount rates 2013.

[61] Manion M, Kleiman G, Rudokas J. Strategic Investments in Residential Energy Efficiency: Insights from NE MARKAL 2006.

[62] Kesicki F. Intertemporal issues and marginal abatement costs in the UK transport sector. Transportation Research Part D: Transport and Environment 2012;17:418-26. doi:10.1016/j.trd.2012.04.002. 
[63] Greene DL. How Consumers Value Fuel Economy: A Literature Review. U.S. EPA; 2010.

[64] Greene DL. Uncertainty, loss aversion, and markets for energy efficiency. Energy Economics 2011;33:608-16. doi:10.1016/j.eneco.2010.08.009.

[65] Energy Information Administration. Assumptions to the Annual Energy Outlook 2015. U.S. DOE; 2015.

[66] Bunch DS, Ramea K, Yeh S, Yang C. Incorporating Behavioral Effects from Vehicle Choice Models into Bottom-Up Energy Sector Models. Davis, CA: UC Davis Institute for Transportation Studies; 2015.

[67] Cayla J-M, Maïzi N. Integrating household behavior and heterogeneity into the TIMESHouseholds model. Applied Energy 2015;139:56-67. doi:10.1016/j.apenergy.2014.11.015.

[68] Daly HE, Ramea K, Chiodi A, Yeh S, Gargiulo M, Gallachóir BÓ. Incorporating travel behaviour and travel time into TIMES energy system models. Applied Energy 2014;135:429-39. doi:10.1016/j.apenergy.2014.08.051.

[69] McCollum DL, Wilson C, Pettifor H, Ramea K, Krey V, Riahi K, et al. Improving the behavioral realism of global integrated assessment models: An application to consumers' vehicle choices. Transportation Research Part D: Transport and Environment 2016. doi:10.1016/j.trd.2016.04.003.

[70] Nguene G, Fragnière E, Kanala R, Lavigne D, Moresino F. SOCIO-MARKAL: Integrating energy consumption behavioral changes in the technological optimization framework. Energy for Sustainable Development 2011;15:73-83. doi:10.1016/j.esd.2011.01.006.

[71] Ramea K, Yang C, Yeh S, Ogden JM. Incorporation of Consumer Demand in Energy Systems Models and their Implications for Climate Policy Analysis, Paris, France: 2013.

[72] Lin Z, Greene D. Who Will More Likely Buy PHEV: A Detailed Market Segmentation Analysis, Shenzhen, China: 2010, p. 1-9.

[73] Lin Z, Greene D. Promoting the Market for Plug-In Hybrid and Battery Electric Vehicles. Transportation Research Record: Journal of the Transportation Research Board 2011;2252:49-56. doi:10.3141/2252-07.

[74] Train KE. Discrete Choice Methods with Simulation. Cambridge University Press; 2009.

[75] Bunch DS, Bradley M, Golob TF, Kitamura R, Occhiuzzo GP. Demand for clean-fuel vehicles in California: A discrete-choice stated preference pilot project. Transportation Research Part A: Policy and Practice 1993;27:237-53. doi:10.1016/0965-8564(93)90062P.

[76] Loulou R, Lavigne D. MARKAL Model with Elastic Demands: Application to Greenhouse Gas Emission Control. In: Carraro C, Haurie A, editors. Operations Research and Environmental Management, Springer Netherlands; 1996, p. 201-20. doi:10.1007/978-94-009-0129-2_9.

[77] Anandarajah G, Strachan N, Ekins P, Kannan R, Hughes N. Pathways to a Low Carbon Economy: Energy systems modelling. London: UKERC; 2008.

[78] Chen W, Wu Z, He J, Gao P, Xu S. Carbon emission control strategies for China: A comparative study with partial and general equilibrium versions of the China MARKAL model. Energy 2007;32:59-72. doi:10.1016/j.energy.2006.01.018.

[79] Anandarajah G, Strachan N. Interactions and implications of renewable and climate change policy on UK energy scenarios. Energy Policy 2010;38:6724-35. 
[80] Kesicki F, Anandarajah G. The role of energy-service demand reduction in global climate change mitigation: Combining energy modelling and decomposition analysis. Energy Policy 2011;39:7224-33. doi:10.1016/j.enpol.2011.08.043.

[81] Pye S, Usher W, Strachan N. The uncertain but critical role of demand reduction in meeting long-term energy decarbonisation targets. Energy Policy 2014;73:575-86. doi:10.1016/j.enpol.2014.05.025.

[82] Wing IS. Computable General Equilibrium Models and Their Use in Economy-Wide Policy Analysis. Cambridge, MA: MIT Joint Program on the Science and Policy of Global Change; 2004.

[83] Hamilton LD, Goldstein GA, Lee J, Marcuse W, Morris SC (Brookhaven NL, Manne AS (Stanford U, et al. Markal-Macro: An Overview. Brookhaven National Lab., Upton, NY (United States); 1992.

[84] Martinsen T. Introducing technology learning for energy technologies in a national CGE model through soft links to global and national energy models. Energy Policy 2011;39:3327-36. doi:10.1016/j.enpol.2011.03.025.

[85] Peters JC. The GTAP-Power Data Base: Disaggregating the Electricity Sector in the GTAP Data Base. Journal of Global Economic Analysis 2016;1:209-50. doi:10.21642/JGEA.010104AF.

[86] Glynn J, Fortes P, Krook-Riekkola A, Labriet M, Vielle M, Kypreos S, et al. Economic Impacts of Future Changes in the Energy System-Global Perspectives. In: Giannakidis G, Labriet M, Ó Gallachóir B, Tosato G, editors. Informing Energy and Climate Policies Using Energy Systems Models, vol. 30, Cham: Springer International Publishing; 2015, p. 333-58.

[87] Jacobsen HK. Integrating the bottom-up and top-down approach to energy-economy modelling: the case of Denmark. Energy Economics 1998;20:443-61. doi:10.1016/S01409883(98)00002-4.

[88] Kypreos S, Lehtila A. TIMES-Macro: Decomposition into Hard-Linked LP and NLP Problems. Energy Technology Systems Analysis Programme; 2014.

[89] Messner S, Schrattenholzer L. MESSAGE-MACRO: linking an energy supply model with a macroeconomic module and solving it iteratively. Energy 2000;25:267-82. doi:10.1016/S0360-5442(99)00063-8.

[90] Trutnevyte E, Barton J, O’Grady Á, Ogunkunle D, Pudjianto D, Robertson E. Linking a storyline with multiple models: A cross-scale study of the UK power system transition. Technological Forecasting and Social Change 2014;89:26-42. doi:10.1016/j.techfore.2014.08.018.

[91] Lempert RJ, Popper S, Bankes S. Shaping the Next One Hundred Years: New Methods for Quantitative, Long-Term Policy Analysis. Rand Corporation; 2003.

[92] Alcamo J. Chapter Six The SAS Approach: Combining Qualitative and Quantitative Knowledge in Environmental Scenarios. In: Alcamo J, editor. Developments in Integrated Environmental Assessment, vol. 2, Elsevier; 2008, p. 123-50.

[93] Schnaars SP. How to develop and use scenarios. Long Range Planning 1987;20:105-14. doi:10.1016/0024-6301(87)90038-0.

[94] Bradfield R, Wright G, Burt G, Cairns G, Van Der Heijden K. The origins and evolution of scenario techniques in long range business planning. Futures 2005;37:795-812. doi:10.1016/j.futures.2005.01.003. 
[95] Godet M. The Art of Scenarios and Strategic Planning: Tools and Pitfalls. Technological Forecasting and Social Change 2000;65:3-22. doi:10.1016/S0040-1625(99)00120-1.

[96] Godet M, Roubelat F. Creating the future: The use and misuse of scenarios. Long Range Planning 1996;29:164-71. doi:10.1016/0024-6301(96)00004-0.

[97] Huss WR, Honton EJ. Scenario planning — What style should you use? Long Range Planning 1987;20:21-9. doi:10.1016/0024-6301(87)90152-X.

[98] Lowe R. Developing International Scenarios for the Rapid Reduction of Carbon Dioxide Emissions from the Built Environment, Maastricht, Netherlands: 2000, p. 5.

[99] Martelli A. Scenario building and scenario planning: state of the art and prospects of evolution. Futures Research Quarterly 2001;17:57-74.

[100] Masini EB, Vasquez JM. Scenarios as Seen from a Human and Social Perspective. Technological Forecasting and Social Change 2000;65:49-66. doi:10.1016/S00401625(99)00127-4.

[101] Hughes N. A historical overview of strategic scenario planning. London, England, UK: UK Energy Research Centre; 2009.

[102] Bishop P, Hines A, Collins T. The current state of scenario development: an overview of techniques. Foresight 2007;9:5-25. doi:10.1108/14636680710727516.

[103] Börjeson L, Höjer M, Dreborg K-H, Ekvall T, Finnveden G. Scenario types and techniques: Towards a user's guide. Futures 2006;38:723-39. doi:10.1016/j.futures.2005.12.002.

[104] Hughes N, Strachan N. Methodological review of UK and international low carbon scenarios. Energy Policy 2010;38:6056-65. doi:10.1016/j.enpol.2010.05.061.

[105] Van Notten P. Scenario development: a typology of approaches. Schooling for Tomorrow: Think Scenarios, Rethink Education, Paris, France: OECD Publishing; 2006, p. 69-84.

[106] van Notten PWF, Rotmans J, van Asselt MBA, Rothman DS. An updated scenario typology. Futures 2003;35:423-43. doi:10.1016/S0016-3287(02)00090-3.

[107] De Jouvenel H. A Brief Methodological Guide to Scenario Building. Technological Forecasting and Social Change 2000;65:37-48. doi:10.1016/S0040-1625(99)00123-7.

[108] Hughes N. Towards improving the relevance of scenarios for public policy questions: A proposed methodological framework for policy relevant low carbon scenarios. Technological Forecasting and Social Change 2013;80:687-98. doi:10.1016/j.techfore.2012.07.009.

[109] Scholz RW, Tietje O. Embedded Case Study Methods: Integrating Quantitative and Qualitative Knowledge. SAGE; 2002.

[110] van 't Klooster SA, van Asselt MBA. Practising the scenario-axes technique. Futures 2006;38:15-30. doi:10.1016/j.futures.2005.04.019.

[111] Schoemaker PJH. Scenario Planning: A Tool for Strategic Thinking. Sloan Management Review 1995;36.2:25-40.

[112] Kann A, Weyant JP. Approaches for performing uncertainty analysis in large-scale energy/economic policy models. Environmental Modeling \& Assessment 2000;5:29-46. doi:10.1023/A:1019041023520.

[113] Schneider SH. What is “dangerous" climate change? Nature 2001;411:17-9. doi:10.1038/35075167.

[114] Grübler A, Nakicenovic N. Identifying dangers in an uncertain climate. Nature 2001;412:15-15. doi:10.1038/35083752. 
[115] Bryant BP, Lempert RJ. Thinking inside the box: A participatory, computer-assisted approach to scenario discovery. Technological Forecasting and Social Change 2010;77:34-49. doi:10.1016/j.techfore.2009.08.002.

[116] Trutnevyte E, Guivarch C, Lempert R, Strachan N. Reinvigorating the scenario technique to expand uncertainty consideration. Climatic Change 2016;135:373-9. doi:10.1007/s10584-015-1585-x.

[117] Pye S, Sabio N, Strachan N. An integrated systematic analysis of uncertainties in UK energy transition pathways. Energy Policy 2015;87:673-84. doi:10.1016/j.enpol.2014.12.031.

[118] Blanford GJ, Kriegler E, Tavoni M. Harmonization vs. fragmentation: overview of climate policy scenarios in EMF27. Climatic Change 2014;123:383-96. doi:10.1007/s10584-0130951-9.

[119] Babonneau F, Haurie A, Loulou R, Vielle M. Combining Stochastic Optimization and Monte Carlo Simulation to Deal with Uncertainties in Climate Policy Assessment. Environ Model Assess 2011;17:51-76. doi:10.1007/s10666-011-9275-1.

[120] Bosetti V, Tavoni M. Uncertain R\&D, backstop technology and GHGs stabilization. Energy Economics 2009;31, Supplement 1:S18-26. doi:10.1016/j.eneco.2008.03.002.

[121] Kanudia A, Loulou R. Robust responses to climate change via stochastic MARKAL: The case of Québec. European Journal of Operational Research 1998;106:15-30. doi:10.1016/S0377-2217(98)00356-7.

[122] Loulou R, Kanudia A. Minimax regret strategies for greenhouse gas abatement: methodology and application. Operations Research Letters 1999;25:219-30. doi:10.1016/S0167-6377(99)00049-8.

[123] Loulou R, Labriet M. ETSAP-TIAM: the TIMES integrated assessment model Part I: Model structure. CMS 2008;5:7-40. doi:10.1007/s10287-007-0046-z.

[124] Manne AS, Richels RG. Buying Greenhouse Insurance: The Economic Costs of Carbon Dioxide Emission Limits. MIT Press; 1992.

[125] Mattsson N. Introducing uncertain learning in an energy system model: a pilot study using GENIE. International Journal of Global Energy Issues 2002;18:253-65. doi:10.1504/IJGEI.2002.000963.

[126] Rockafellar RT, Wets RJ-B. Scenarios and Policy Aggregation in Optimization Under Uncertainty. MATHEMATICS OF OPERATIONS RESEARCH 1991;16:119-47. doi:10.1287/moor.16.1.119.

[127] Pereira MVF, Pinto LMVG. Multi-stage stochastic optimization applied to energy planning. Mathematical Programming 1991;52:359-75. doi:10.1007/BF01582895.

[128] Queiroz ARD. A Sampling-based Decomposition Algorithm with Application to Hydrothermal Scheduling: Cut Formation and Solution Quality. University of Texas at Austin, 2011.

[129] Brill ED, Flach JM, Hopkins LD, Ranjithan S. MGA: A Decision Support System for Complex, Incompletely Defined Problems. IEEE Transactions on Systems, Man, and Cybernetics 1990;20:745-57.

[130] Brill ED, Chang S-Y, Hopkins LD. Modeling to generate Alternatives: The HSJ Approach and an Illustration Using a Problem in Land Use Planning. Management Science 1982;28:221-35.

[131] DeCarolis JF. Using modeling to generate alternatives (MGA) to expand our thinking on energy futures. Energy Economics 2011;33:145-52. 
[132] DeCarolis JF, Babaee S, Li B, Kanungo S. Modelling to generate alternatives with an energy system optimization model. Environmental Modelling \& Software 2016;79:30010. doi:10.1016/j.envsoft.2015.11.019.

[133] Trutnevyte E. EXPANSE methodology for evaluating the economic potential of renewable energy from an energy mix perspective. Applied Energy 2013;111:593-601. doi:10.1016/j.apenergy.2013.04.083.

[134] Price J. Modelling to generate alternatives: A technique to explore uncertainty in energyenvironment-economy models, Cork, Ireland: 2016.

[135] Li FGN, Trutnevyte E. Investment appraisal of cost-optimal and near-optimal pathways for the UK electricity sector transition to 2050. Applied Energy 2017;189:89-109. doi:10.1016/j.apenergy.2016.12.047.

[136] Peace J, Weyant J. Insights Not Numbers: The Appropriate Use of Economic Models. Pew Center on Global Climate Change; 2008.

[137] Kloprogge P, van der Sluijs J, Wardekker A. Uncertainty Communication: Issues and good practice. Utrecht, Netherlands: Copernicus Institute for Sustainable Development and Innovation, Department of Science Technology and Society (STS); 2007.

[138] Schneider SH. Integrated assessment modeling of global climate change: Transparent rational tool for policy making or opaque screen hiding value-laden assumptions? Environmental Modeling \& Assessment 1997;2:229-49. doi:10.1023/A:1019090117643.

[139] Pidgeon N, Demski C, Butler C, Parkhill K, Spence A. Creating a national citizen engagement process for energy policy. PNAS 2014;111:13606-13. doi:10.1073/pnas.1317512111.

[140] Wong-Parodi G, Fischhoff B, Strauss B. A method to evaluate the usability of interactive climate change impact decision aids. Climatic Change 2014;126:485-93. doi:10.1007/s10584-014-1226-9.

[141] Saltelli A, Funtowicz S. When All Models Are Wrong. Issues in Science and Technology 2014;30:79-85.

[142] Trutnevyte E, McDowall W, Tomei J, Keppo I. Energy scenario choices: Insights from a retrospective review of UK energy futures. Renewable and Sustainable Energy Reviews 2016;55:326-37. doi:10.1016/j.rser.2015.10.067.

[143] Committee on Climate Change. Building a low-carbon economy - The UK's contribution to tackling climate change. London, UK: Committee on Climate Change; 2008.

[144] DECC. The Carbon Plan: Delivering our low carbon future. London, UK: Department of Energy and Climate Change; 2011.

[145] Taylor PG, Upham P, McDowall W, Christopherson D. Energy model, boundary object and societal lens: 35 years of the MARKAL model in the UK. Energy Research \& Social Science 2014;4:32-41. doi:10.1016/j.erss.2014.08.007.

[146] Strachan N. UK energy policy ambition and UK energy modelling-fit for purpose? Energy Policy 2011;39:1037-40. doi:10.1016/j.enpol.2011.01.015.

[147] Strachan N, Fais B, Daly H. Reinventing the energy modelling-policy interface. Nature Energy 2016;1:16012. doi:10.1038/nenergy.2016.12.

[148] EKINS P, ANANDARAJAH G, STRACHAN N. Towards a low-carbon economy: scenarios and policies for the UK. Climate Policy 2011;11:865-82. doi:10.3763/cpol.2010.0126. 
[149] Jablonski S, Strachan N, Brand C, Bauen A. The role of bioenergy in the UK's energy future formulation and modelling of long-term UK bioenergy scenarios. Energy Policy 2010;38:5799-816. doi:10.1016/j.enpol.2010.05.031.

[150] Strachan N, Pye S, Kannan R. The iterative contribution and relevance of modelling to UK energy policy. ENERGY POLICY 2009;37:850-60. doi:10.1016/j.enpol.2008.09.096.

[151] STRACHAN N, PYE S, HUGHES N. The role of international drivers on UK scenarios of a low-carbon society. Climate Policy 2008;8:S125-39. doi:10.3763/cpol.2007.0489.

[152] Chaudry M, Ekins P, Ramachandran K, Shakoor A, Skea J, Strbac G, et al. Building a Resilient UK Energy System. London, UK: 2011.

[153] Strachan N, Kannan R. Hybrid modelling of long-term carbon reduction scenarios for the UK. Energy Economics 2008;30:2947-63. doi:10.1016/j.eneco.2008.04.009.

[154] Daly HE, Scott K, Strachan N, Barrett J. Indirect CO2 Emission Implications of Energy System Pathways: Linking IO and TIMES Models for the UK. Environ Sci Technol 2015;49:10701-9. doi:10.1021/acs.est.5b01020.

[155] Strachan N, Usher W. Failure to achieve stringent carbon reduction targets in a secondbest policy world. Climatic Change 2012;113:121-39. doi:10.1007/s10584-011-0267-6.

[156] Usher W, Strachan N. Critical mid-term uncertainties in long-term decarbonisation pathways. Energy Policy 2012;41:433-44. doi:10.1016/j.enpol.2011.11.004.

[157] Committee on Climate Change. The Fourth Carbon Budget - reducing emissions through the 2020s. London, UK: Committee on Climate Change; 2010.

[158] UNFCCC. Paris Agreement. United Nations Office at Geneva; 2015.

[159] ISO. ISO 14040:2006 - Environmental management -- Life cycle assessment -- Principles and framework. ISO 2006.

http://www.iso.org/iso/home/store/catalogue_tc/catalogue_detail.htm?csnumber=37456 (accessed July 7, 2016).

[160] PRé. LCA Discussion List | PRé Sustainability 2016. https://www.presustainability.com/lca-discussion-list (accessed July 7, 2016). 